\title{
Approach to the diagnosis of secondary hypertension in adults
}

\section{SUMMARY}

Presentations that should raise suspicion of secondary hypertension include early-onset, severe or resistant hypertension. A suggestive family history or clinical clues can point to a specific secondary cause.

The most common causes and associations are renal disease, primary aldosteronism and obstructive sleep apnoea. Medicines, illicit substances and alcohol may also be responsible.

The assessment of patients begins with history taking and examination, to look for clinical clues. Laboratory tests include electrolytes, urea, creatinine and the aldosterone:renin ratio, urinalysis and the urine albumin:creatinine ratio. Abnormal results should prompt further investigation.

Initial testing for primary aldosteronism is best done before starting potentially interfering antihypertensive drugs. If the patient is already taking interfering antihypertensive drugs that cannot be stopped, the interpretation of the aldosterone:renin ratio must consider the presence of those drugs. Specialist advice can be sought if needed.

\section{Introduction}

Secondary hypertension occurs in approximately $10 \%$ of adults with hypertension. ' There are many possible causes (Table 1). Identifying and treating the cause can potentially cure or markedly improve hypertension and reduce the associated cardiovascular risk.1,2

The history and examination may raise suspicion of secondary hypertension. It is important to remember that drugs can cause hypertension. Laboratory tests can help to identify other causes.

\section{Who should be assessed for secondary hypertension?}

International and local guidelines differ in their recommendations and prescriptiveness in relation to screening for secondary causes of hypertension. In general, patients with hypertension and any of the following characteristics should be screened:1,3

- age of onset less than 40 years

- abrupt onset of hypertension

- abrupt worsening of hypertension despite previously good control

- $\quad$ hypertensive urgency or emergency

- resistant hypertension (blood pressure $\geq 140 / 90 \mathrm{mmHg}$ despite the consistent use of three antihypertensive drugs including a diuretic, or a need for four or more drugs to control the blood pressure)
- $\quad$ target organ damage disproportionate to the degree of hypertension

- family history of early-onset hypertension, stroke before the age of 40 years, or primary aldosteronism

- clinical clues

- hypokalaemia (may occur in primary aldosteronism)

- $\quad$ higher elevation than expected (>20\%) of serum creatinine after starting an ACE inhibitor or angiotensin receptor antagonist (may suggest renovascular hypertension)

- paroxysmal hypertension or episodes suggestive of catecholamine excess (suggestive of phaeochromocytoma).

All patients suspected of having secondary hypertension should be screened for the common causes and associations. These include renal disease (parenchymal or renovascular), primary aldosteronism, medicines, illicit substances, alcohol and obstructive sleep apnoea. Other, less prevalent causes should only be investigated if there is strong clinical suspicion of a particular disorder, such as coarctation of the aorta. It is important to remember that a lack of adherence to antihypertensive treatment can cause persistent hypertension.

\section{Ranita Siru ii}

Endocrinologist and Chemical pathology registrar ${ }^{1}$

\section{Johan H Conradie}

Head of Biochemistry and Chemical pathologist ${ }^{1}$

\section{Melissa J Gillett}

Chemical pathologist and Endocrinologist ${ }^{1}$

Head of Biochemistry and Chemical pathologist ${ }^{2}$

\section{Michael M Page (iD)}

Chemical pathologist'

\section{'Department of}

Biochemistry, Western

Diagnostic Pathology

2 Department of

Biochemistry, PathWest Laboratory Medicine, Fiona Stanley Hospital

Perth

\section{Keywords}

aldosteronism,

antihypertensive

drugs, blood pressure,

hypertension

Aust Prescr 2021:44:165-9 https://doi.org/10.18773/ austprescr.2021.038 


\section{Table 1 Laboratory tests in the initial investigation of secondary hypertension}

\begin{tabular}{|c|c|c|c|}
\hline Cause* & $\begin{array}{l}\text { Prevalence } \\
\text { in unselected } \\
\text { hypertensive } \\
\text { patients }\end{array}$ & Clinical clues & Laboratory tests \\
\hline Renovascular disease $^{+}$ & $5 \%$ & $\begin{array}{l}\text { Acute worsening of renal function after starting } \\
\text { an ACE inhibitor or angiotensin receptor } \\
\text { antagonist, flash pulmonary oedema, early-onset } \\
\text { hypertension in a female, abdominal bruit }\end{array}$ & $\begin{array}{l}\text { Electrolytes and creatinine with eGFR } \\
\text { Urinalysis } \\
\text { Urine albumin:creatinine ratio }\end{array}$ \\
\hline $\begin{array}{l}\text { Renal parenchymal } \\
\text { disease }^{+}\end{array}$ & $1 \%$ & $\begin{array}{l}\text { Haematuria, proteinuria, history of recurrent } \\
\text { urinary tract infections or obstruction, family } \\
\text { history, polycystic kidneys, abdominal mass }\end{array}$ & $\begin{array}{l}\text { Electrolytes and creatinine with eGFR } \\
\text { Urinalysis } \\
\text { Urine albumin:creatinine ratio }\end{array}$ \\
\hline Primary aldosteronism & $8 \%$ & Hypokalaemia & Aldosterone:renin ratio \\
\hline $\begin{array}{l}\text { Drugs, alcohol and other } \\
\text { substances }\end{array}$ & $2 \%$ & $\begin{array}{l}\text { Drug history, NSAIDs, SNRIs, decongestants, oral } \\
\text { contraceptives, bupropion, ciclosporin, tacrolimus, } \\
\text { cocaine, amphetamines, caffeine, nicotine, } \\
\text { alcohol, liquorice, some herbal supplements }\end{array}$ & \\
\hline Cushing's syndrome & $<1 \%$ & $\begin{array}{l}\text { Striae (purplish-red), proximal muscle wasting, } \\
\text { easy bruising, thin skin, rapid weight gain, central } \\
\text { adiposity, moon facies, buffalo hump, pathologic } \\
\text { fracture, diabetes mellitus }\end{array}$ & $\begin{array}{l}\text { Late night salivary cortisol on two occasions } \\
\text { Free cortisol in } 24 \text {-hour urine on two occasions } \\
1 \text { mg overnight dexamethasone suppression test } \\
\text { Measuring a morning or random serum cortisol } \\
\text { is not recommended owing to a low sensitivity } \\
\text { and specificity for Cushing's syndrome }\end{array}$ \\
\hline $\begin{array}{l}\text { Phaeochromocytoma/ } \\
\text { paraganglioma }\end{array}$ & $<1 \%$ & $\begin{array}{l}\text { Paroxysms or 'spells': headache, palpitations, } \\
\text { sweating, pallor, labile blood pressure }\end{array}$ & Plasma metanephrines \\
\hline Aortic coarctation ${ }^{\dagger}$ & $<1 \%$ & $\begin{array}{l}\text { Well-developed upper body, hypertension } \\
\text { confined to the upper limbs, systolic murmur }\end{array}$ & \\
\hline Obstructive sleep apnoea $\ddagger$ & $25 \%$ & Snoring, daytime somnolence, morning headache & \\
\hline
\end{tabular}

eGFR estimated glomerular filtration rate NSAIDs non-steroidal anti-inflammatory drugs SNRIs serotonin noradrenaline reuptake inhibitors

* Other rare causes of secondary hypertension include acromegaly, thyroid dysfunction and primary hyperparathyroidism.

+ Laboratory tests should be complemented by imaging.

$\ddagger$ Obstructive sleep apnoea has a very strong and important association, but may not be a cause of secondary hypertension.

\section{Initial tests for primary aldosteronism}

Patients with primary aldosteronism have a higher risk of cardiovascular morbidity and mortality than other age-, sex- and blood pressure-matched patients. ${ }^{3}$ Although testing for primary aldosteronism has not been directly linked with mortality benefits, treating primary aldosteronism surgically (by unilateral adrenalectomy) or with specific mineralocorticoid blockade may improve long-term cardiovascular outcomes. ${ }^{4}$

Hypertension is often the only sign of primary aldosteronism. Most patients do not present with the classical feature of hypokalaemia.

Screening for primary aldosteronism is straightforward if the patient has not started antihypertensive therapy. This involves a blood test, in an unfasted patient who has been ambulatory for at least two hours. It measures aldosterone and renin, allowing calculation of the aldosterone:renin ratio. ${ }^{3}$ This ratio is important as some patients with primary aldosteronism will have normal concentrations of aldosterone. As hypokalaemia can cause a false-negative ratio, potassium should be concurrently measured.

Reference intervals and screening thresholds for aldosterone, renin and their ratio vary according to the laboratory's method of measurement (laboratories may measure either direct renin or plasma renin activity). The ratio should be interpreted in the context of the absolute values for aldosterone and renin. For example, a raised ratio due to a very high aldosterone with a nonsuppressed renin concentration may be more suggestive of secondary hyperaldosteronism due to diuretic use or other causes. The ratio could also be raised because of a very low renin, even if the aldosterone concentration is not as high as is typically seen in primary aldosteronism. 
The finding of an increased aldosterone:renin ratio not explained by interfering antihypertensives and confirmed on more than one occasion should prompt referral to a physician with an interest in hypertension, for consideration of confirmatory dynamic testing and specific treatment.

\section{Effect of antihypertensive drugs}

Although most antihypertensives affect the plasma concentrations of aldosterone, renin and their ratio (see Fig. and Table 2), additional indications may prevent the suspension of some drugs, such as when a beta blocker is also being used to control an arrhythmia. Initial testing therefore often needs to take place while the patient is still taking interfering antihypertensives. Interpreting an aldosterone:renin ratio while a patient is taking interfering antihypertensives can be difficult. Documenting the patient's antihypertensive drugs on the request form will assist the pathologist's analysis.

A suppressed renin, high aldosterone and raised ratio in a patient taking an ACE inhibitor alone (expected to increase renin and decrease aldosterone) would be suspicious for primary aldosteronism. However, a normal ratio in the same patient would not exclude primary aldosteronism, as it may be a false negative. On the other hand, beta blockers decrease renin concentrations. A patient taking a beta blocker who has a non-suppressed renin concentration probably does not have primary aldosteronism, but a suppressed renin and a raised ratio could be a falsepositive result.

Sometimes, substitution of interfering antihypertensives with non-interfering antihypertensives is required to obtain a reliable ratio. This is also important for further confirmatory testing that may follow initial screening. Table 3 shows non-interfering antihypertensives that may be used during the workup to control blood pressure. ${ }^{5}$ As adjusting the antihypertensive regimen can be a lengthy process and is not without risks, it should only be pursued for patients expected to benefit from the diagnosis and treatment of primary aldosteronism. A discussion with a physician with a special interest in

\section{Fig. Effects of interfering drugs on aldosterone and renin}

Aldosterone acts on mineralocorticoid receptors in the kidneys to increase salt and water retention, increasing blood pressure and supressing renin. Spironolactone blocks these receptors, which significantly increases both renin and aldosterone.

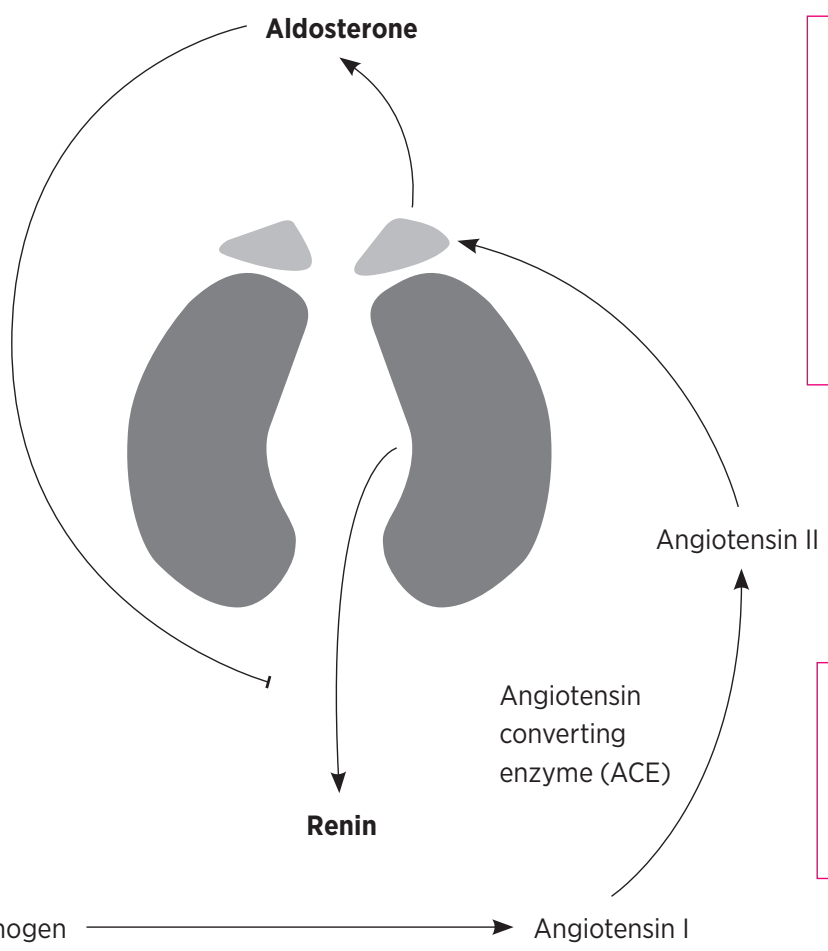

Angiotensin II acts on the AT, receptor, stimulating aldosterone secretion from the adrenal glands. Angiotensin receptor antagonists prevent this, thereby reducing aldosterone, increasing renin and reducing the ARR. Dihydropyridine calcium channel blockers also inhibit aldosterone secretion, increase renin and reduce the ARR.

Angiotensin

Renin is secreted by the kidneys in volume depleted states. It converts angiotensinogen to angiotensin I. Diuretics increase renin, which increases aldosterone as a consequence. Renin is also under sympathetic control via beta-1 receptors. Beta blockers suppress renin, which can increase the ARR. 
Table 2 Factors that may lead to false-positive or false-negative aldosterone:renin ratio results

\begin{tabular}{|c|c|c|c|}
\hline Factor & $\begin{array}{l}\text { Effect on } \\
\text { aldosterone plasma } \\
\text { concentration }\end{array}$ & $\begin{array}{l}\text { Effect on renin } \\
\text { concentration }\end{array}$ & $\begin{array}{l}\text { Effect on } \\
\text { aldosterone:renin } \\
\text { ratio }\end{array}$ \\
\hline \multicolumn{4}{|l|}{ Drugs* } \\
\hline Beta adrenergic blockers & $\downarrow$ & $\downarrow \downarrow$ & $\uparrow(F P)$ \\
\hline Central agonists (e.g. clonidine, alpha methyldopa) & $\downarrow$ & $\downarrow \downarrow$ & $\uparrow(F P)$ \\
\hline Non-steroidal anti-inflammatory drugs & $\downarrow$ & $\downarrow \downarrow$ & $\uparrow(F P)$ \\
\hline Potassium wasting diuretics & $\rightarrow \uparrow$ & $\uparrow \uparrow$ & $\uparrow(\mathrm{FN})$ \\
\hline Potassium sparing diuretics & $\uparrow$ & $\uparrow \uparrow$ & $\downarrow(F N)$ \\
\hline ACE inhibitors & $\downarrow$ & $\uparrow \uparrow$ & $\downarrow(F N)$ \\
\hline Angiotensin receptor antagonist & $\downarrow$ & $\uparrow \uparrow$ & $\downarrow(F N)$ \\
\hline Calcium channel blockers (dihydropyridines) & $\rightarrow \downarrow$ & $\uparrow$ & $\downarrow(F N)$ \\
\hline \multirow[t]{2}{*}{ Renin inhibitors } & $\downarrow$ & $\downarrow \uparrow$ & $\uparrow(F P)$ \\
\hline & & & $\downarrow(F N)$ \\
\hline \multicolumn{4}{|l|}{ Potassium status } \\
\hline Hypokalaemia & $\downarrow$ & $\rightarrow \uparrow$ & $\downarrow(F N)$ \\
\hline Potassium loading & $\uparrow$ & $\rightarrow \downarrow$ & $\uparrow$ \\
\hline \multicolumn{4}{|l|}{ Dietary sodium } \\
\hline Sodium restriction & $\uparrow$ & $\uparrow \uparrow$ & $\uparrow(\mathrm{FN})$ \\
\hline Sodium loading & $\downarrow$ & $\downarrow \downarrow$ & $\uparrow(F P)$ \\
\hline Advancing age & $\downarrow$ & $\downarrow \downarrow$ & $\uparrow(F P)$ \\
\hline Premenopausal women (vs males) ${ }^{\dagger}$ & $\rightarrow \uparrow$ & $\downarrow$ & $\uparrow(F P)$ \\
\hline \multicolumn{4}{|l|}{ Other conditions } \\
\hline Renal impairment & $\rightarrow$ & $\downarrow$ & $\uparrow(F P)$ \\
\hline PHA-2 & $\rightarrow$ & $\downarrow$ & $\uparrow(F P)$ \\
\hline Pregnancy & $\uparrow$ & $\uparrow \uparrow$ & $\downarrow(F N)$ \\
\hline Renovascular hypertension & $\uparrow$ & $\uparrow \uparrow$ & $\downarrow(F N)$ \\
\hline Malignant hypertension & $\uparrow$ & $\uparrow \uparrow$ & $\downarrow(F N)$ \\
\hline
\end{tabular}

FN false negative $\quad$ FP false positive

$\downarrow$ decreases effect $\quad \uparrow$ increases effect $\rightarrow$ has no effect

PHA-2 pseudohypoaldosteronism type 2 (familial hypertension and hyperkalaemia with normal glomerular filtration rate)

* Renin inhibitors lower plasma renin activity, but raise direct renin concentration. This would be expected to result in false-positive aldosterone:renin ratios for renin measured as plasma renin activity and false negatives for renin measured as direct renin concentration.

${ }^{\dagger}$ In premenopausal, ovulating women, plasma aldosterone concentrations measured during the menses or the proliferative phase of the menstrual cycle are similar to those of men but rise briskly in the luteal phase. Because renin concentrations are lower, the aldosterone:renin ratio is higher than in men for all phases of the cycle, but especially during the luteal phase during which aldosterone rises to a greater extent than renin. False positives can occur during the luteal phase, but only if renin is measured as direct renin concentration and not plasma renin activity. In preliminary studies, some investigations have found false positives on the current cut-offs for women in the luteal phase. Accordingly, it would seem sensible to screen women at risk in the follicular phase, if practicable.

Source: adapted from reference 3 


\section{Table 3 Drugs that do not interfere with calculating the aldosterone:renin ratio ${ }^{5}$}

\begin{tabular}{lll} 
& Starting dose & Maximum dose \\
\hline Sustained-release verapamil* & $180 \mathrm{mg}$ daily & $240 \mathrm{mg}$ daily \\
Moxonidine & 200 micrograms once at night & 200 micrograms twice daily after two weeks \\
Prazosin & $0.5 \mathrm{mg}$ twice daily & $5 \mathrm{mg}$ three times a day \\
Hydralazine hydrochloride & $12.5 \mathrm{mg}$ twice daily & $50 \mathrm{mg}$ three times a day \\
\hline
\end{tabular}

* Administration of verapamil as two divided doses may provide better coverage over 24 hours, if necessary. Doses higher than 240 mg daily may be used, but are often limited by adverse effects, therefore addition of a second drug is advised before increasing the verapamil dose.

hypertension should be considered, and the patient should understand why changes to their treatment are being proposed.

When adjusting the antihypertensive regimen, drugs are usually ceased one at a time at a rate of one per week, or more slowly if there is a need to maintain blood pressure control. Diuretics including spironolactone are stopped first, as they require a washout of at least four weeks. Other antihypertensives need to be ceased for a minimum of two weeks before testing. ${ }^{3}$ Blood pressure should be monitored at least twice a week. Home blood pressure monitoring can be helpful for selected patients. Non-interfering antihypertensives, if required, may be introduced and up-titrated one at a time. The target blood pressure may be individualised based on the patient's previous blood pressure, their age and the duration of hypertension. This blood pressure may be higher than the usual target for the prevention of cardiovascular disease, given that these drug substitutions are only temporary.

Patients should be informed of the symptoms of a hypertensive emergency, what a safe blood pressure is and how to seek medical attention if their blood pressure exceeds this. Provide counselling about the adverse effects, the frequency of dosing for the noninterfering antihypertensives, and the precautions for driving.

\section{Conclusion}

Identifying secondary hypertension presents an opportunity to modify a patient's cardiovascular risk profile beyond what is achievable by antihypertensive therapy alone. Renal disease and primary aldosteronism are common causes.

A methodical approach to identifying the cause is necessary and must take into account the drugs being used by the patient. Advice on test selection and patient preparation to optimise the value of initial investigations can be provided by a chemical pathologist or hypertension specialist. Patients who have abnormal results will require further investigations to confirm the cause. $\varangle$

Conflicts of interest: none declared

\section{REFERENCES}

1. Whelton PK, Carey RM, Aronow WS, Casey DE Jr, Collins KJ, Dennison Himmelfarb C, et al. 2017 ACC/AHA/AAPA/ABC/ ACPM/AGS/APhA/ASH/ASPC/NMA/PCNA Guideline for the prevention, detection, evaluation, and management of high blood pressure in adults: a report of the American College of Cardiology/American Heart Association Task Force on Clinical Practice Guidelines. Circulation 2018;138:e484-594. https://doi.org/10.1161/cir.0000000000000596

2. Williams B, Mancia G, Spiering W, Agabiti Rosei E Azizi M, Burnier M, et al. 2018 Practice guidelines for the management of arterial hypertension of the European Society of Cardiology and the European Society of Hypertension. Blood Press 2018;27:314-40. https://doi.org/ 10.1080/08037051.2018.1527177
3. Funder JW, Carey RM, Mantero F, Murad MH, Reincke M, Shibata $\mathrm{H}$, et al. The management of primary aldosteronism: case detection, diagnosis, and treatment: an Endocrine Society clinical practice guideline. J Clin Endocrinol Metab 2016;101:1889-916. https://doi.org/10.1210/jc.2015-4061

4. Hundemer GL. Primary aldosteronism: cardiovascular outcomes pre- and post-treatment. Curr Cardiol Rep 2019;21:93. https://doi.org/10.1007/s11886-019-1185-x

5. Gurgenci T, Geraghty S, Wolley M, Yang J. Screening for primary aldosteronism: How to adjust existing antihypertensive medications to avoid diagnostic errors. Aust J Gen Pract 2020:49:127-31. https://doi.org/10.31128/ AJGP-07-19-4995

\section{SELF-TEST QUESTIONS}

True or false?

3. Most patients who have primary aldosteronism also have hypokalaemia.

4. A high aldosterone:renin ratio in a patient taking an ACE inhibitor suggests primary aldosteronism.

Answers on page 177

\section{FURTHER READING}

Gabb G. What is hypertension? Aust Prescr 2020;43:108-9.

https://doi.org/10.18773/austprescr.2020.025 